\title{
Investigação das atividades antioxidante e antimicrobiana de duas espécies arbóreas ocorrentes no bioma caatinga
}

\author{
Fábio Rogério Santos Nunes ${ }^{1}$, Hosana Maria Cordeiro Dias ${ }^{2} \mathrm{e}$ \\ Giani Maria Cavalcante ${ }^{3}$
}

1 Graduando do Curso de Biologia do Centro Universitário Cesmac, Maceió, AL, Brasil. E-mail: fabiorbiologia@bol.com.br 2 Graduando do Curso de Biologia do Centro Universitário Cesmac, Maceió, AL, Brasil. E-mail: hosanamcdias@bol.com.br

3 Mestre em Ciências Biológicas. Bióloga. Professora do Centro Universitário Cesmac, Maceió, AL, Brasil. E-mail: gianimc@icloud.com

RESUMO: O bioma caatinga é um bioma brasileiro predominante e único no Nordeste do Brasil. Esse bioma abriga uma impressionante biodiversidade florística com espécies ricas em moléculas bioativas. O objetivo deste trabalho foi investigar a atividade antioxidante e antimicrobiana de duas espécies vegetais arbóreas ocorrentes na caatinga. Nos ensaios de atividade antioxidante dos extratos etanólicos da casca do caule das espécies Leucaena leucocephala e Cnidoscolus quercifolius foram avaliados o teor de fenólicos totais e atividade antioxidante pelos métodos de captura dos radicais livres DPPH (radical 1,1-diphenil-2-picrilhydrazil) e ABTS (radical 2,2'azinobis-(3-ethylbenzthiazoline-6-sulfonic acid)). A atividade antimicrobiana desses extratos foi avaliada frente às espécies bacterianas Enterococcus faecales (ATCC 29212), Streptococcus pneumoniae (ATCC 49619) e Staphylococcus aureus (ATCC 25923), através do ensaio de difusão em poço e determinação de Concentração Inibitória Mínima (CIM). Os teores de fenólicos totais encontrados na espécie $L$. leucocephala exibiram quantidades relevantes de polifenóis, resultado não observado na espécie $C$. quercifolius. Foi observado existir uma correlação direta entre a quantidade de fenólicos totais e a atividade antioxidante das espécies testadas. Nenhuma das espécies apresentou atividade antimicrobiana significativa.

Palavras-chaves: Atividades biológicas. Leucaena leucocephala. Cnidoscolus quercifolius.

Investigation of antioxidant and antimicrobial activities of two tree species of the biome caatinga

ABSTRACT: The caatinga biome is a unique Brazilian biome predominant in the Northeast of Brazil. This biome hosts an impressive floristic biodiversity with species rich in molecules bioactives. The aim of study was investigate the antioxidant and antimicrobial activities of tree species occurring in caatinga. The antioxidant activity crude extracts of stem bark of Leucaena leucocephala and Cnidoscolus quercifolius were performed evaluating the total phenolic content and antioxidant activity in vitro by the method of capture of free radicals: DPPH (1,1-radical diphenil-2-picrilhydrazil) and ABTS (2,2 'azinobis-(3-ethylbenzthiazoline-6-sulfonic acid)). The antimicrobial activity those extracts were performed against strains of Enterococcus faeca- 
les (ATCC 29212), Streptococcus pneumoniae (ATCC 49619) e Staphylococcus aureus (ATCC 25923) by a diffusion assay in agar and determination of Minimum Inhibiory Concentration (MIC). The levels of phenolics found in the L. leucocephala exhibited relevant quantities of polyphenols, which was not observed in the species $C$. quercifolius. We observed that a direct correlation exists between the amount of total phenolics and antioxidant activity the species tested. The species tested not has significant antimicrobial activity.

Keywords: Biological activities. Leucaena leucocephala. Cnidoscolus quercifolius.

\section{INTRODUÇÃO}

Historicamente as plantas são fontes para uma ampla variedade de antioxidantes naturais e as biomoléculas isoladas de vegetais tem tido suas atividades biológicas, como antimicrobiana, antifúngica, antiparasitária, antitumoral, imunomoduladora, anti-inflamatória e cicatrizante, entre outras, constantemente registradas (RAFIEIANKOPAEI, 2012).

Segundo Mishra e Tiwari (2011), os produtos químicos derivados de vegetais são decorrentes de fenômenos intrínsecos à biodiversidade, em que as interações entre os organismos e o meio ambiente fazem com que os primeiros formulem complexos químicos que melhoram sua sobrevivência e competitividade, complexos químicos esses que em geral são potencialmente ativos.

Atualmente as investigações por substâncias com efeito antioxidante e antimicrobiano têm sido emergentes e imperativas. As substâncias com efeito antioxidante são investigadas devido às descobertas sobre o efeito dos radicais livres, que em geral, reagem com substratos biológicos podendo ocasionar danos às moléculas, estando relacionados, principalmente, com patologias cardiovasculares (PAULA; SAN-
TOS; PINTO, 2015). Por sua vez, as investigações sobre as atividades antimicrobianas de substâncias naturais emergem da necessidade de se buscar novos tratamentos que minimizem a resistência desenvolvida pelos microrganismos frente aos antimicrobianos disponíveis para tratamento ( $\mathrm{FAUCl}$; MARSTON, 2014).

A caatinga é um ecossistema heterogêneo que ocupa uma área de $826.411 \mathrm{Km}^{2}$, sendo o principal ecossistema/bioma da região nordeste do Brasil, com um clima quente e seco, semiárido, vegetação xerófila e que apresenta uma vasta diversidade florística (RODAL; SAMPAIO, 2002). Em virtude dessa diversidade florística, o bioma caatinga apresenta-se como uma fonte potencial de novas moléculas bioativas, as quais precisam ter suas atividades biológicas investigadas continuamente, uma vez que várias ações farmacológicas têm sido reportadas paras as espécies ocorrentes nesse bioma (SILVA, COELHO; SILVA, 2015). Como, por exemplo, o trabalho de Araújo et al. (2011), que registraram ação coagulante de lecitinas isoladas da espécie Crateva tapia $\mathrm{L}$.

Neste contexto, vislumbrando conhecer as atividades biológicas de espécies ocorrentes na caatinga, foram escolhidas as espécies Leucaena leucocephala e Cnidoscolus 
quercifolius para investigar as atividades antioxidante e antimicrobiana, como uma triagem inicial para trabalhos com substâncias isoladas dessas espécies.

A espécie L. leucocephala (Lam.) De Wit pertence a família Leguminosa-Mimosoideae e encontra-se amplamente distribuída na caatinga (RIZINNI, 1995). O extrato aquoso do fruto dessa espécie foi testado em animais e apresentou-se como potencial adjuvante no tratamento de diabetes mellitus tipo 2 (KUPPUSAMY et al., 2014). Enquanto, a espécie Cnidoscolus quercifolius Pohl pertence à família Euphorbiaceae. É uma planta endêmica do Brasil e típica do bioma caatinga (BRAGA, 2005). Popularmente essa espécie é usada como agente anti-inflamatório, analgésico, diurético, cicatrizante e antitumoral (AGRA et al, 2007) e de acordo com Ribeiro-Filho (2007) o látex é usado como coagulante sanguíneo e o cataplasma da entrecasca para cicatrização de feridas.

Deste modo, o objetivo desse trabalho foi investigar as atividades antioxidante e antimicrobiana dos extratos da casca do caule das espécies Leucaena leucocephala e Cnidoscolus quercifolius coletadas na região de caatinga do Nordeste brasileiro.

\section{MATERIAIS E MÉTODOS}

Obtenção do material vegetal e dos extratos etanólicos

As espécies vegetais foram obtidas em uma área de cultivo familiar mantida em sistema agroflorestal na cidade de Palmeira dos Índios - AL. Partes vegetais das plantas foram coletadas para identificação das espécies junto ao Instituto de Meio Ambiente de Alagoas (IMA/AL). As exsicatas foram produzidas e depositadas no Herbário do
IMA-AL, com as identificações de números: IMAL-9638 para a espécie $C$. quercifolius e IMAL-9976 para a espécie L. leucocephala.

Para obtenção dos extratos, as cascas de caule foram submetidas à secagem em estufa a $60^{\circ} \mathrm{C}$ por 24 horas, trituradas e extraídas, separadamente, com etanol. Com o auxílio de um rotaevaporador, foi realizada a evaporação do solvente, obtendo-se o extrato da casca do caule de $C$. quercifolius (ECCQ) e o extrato da casca do caule de $L$. leucocephala. (ECLL).

\section{Atividade antioxidante}

A atividade antioxidante dos extratos foi investigada através dos ensaios: Teor de fenólicos totais, Atividade sequestradora do radical DPPH e Atividade sequestradora do cátion radical $\mathrm{ABTS}^{+}$.

O teor de fenólicos totais foi determinado pelo método espectrofotométrico de Folin-Ciocalteu, conforme a metodologia descrita por Vieira, Sousa e Mancini-Filho (2011). Uma alíquota de $0,5 \mathrm{~mL}$ do extrato foi colocada em um tubo de ensaio, e em seguida foi adicionado $8 \mathrm{~mL}$ de água destilada e $0,5 \mathrm{~mL}$ do reagente Folin-Cicoalteau. A mistura foi homogeneizada e, após $3 \mathrm{mi}-$ nutos, foi acrescentado $1 \mathrm{~mL}$ de solução saturada de carbonato de sódio $\left(\mathrm{Na}_{2} \mathrm{CO}_{3}\right)$. Após esse procedimento a solução foi deixada em repouso por $1 \mathrm{~h}$ e uma vez transcorrido esse tempo, foi realizado as leituras das absorbâncias em espectrofotômetro a $720 \mathrm{~nm}$. As análises foram realizadas em triplicata e o teor de fenólicos totais (FT) foi determinado por interpolação da absorbância das amostras contra uma curva de calibração construída com soluções do padrão do ácido gálico nas concentrações de 2; 5; 10; 15 e $20 \mu \mathrm{g} / \mathrm{mL}$. A partir da equação da reta obtida, realizou-se o cálculo do teor de 
fenólicos totais, expresso como miligrama equivalente de ácido gálico/100 g de amostra.

O ensaio de DPPH foi realizado conforme a metodologia descrita por Paula, Santos e Pinto (2015), com algumas modificações. Os extratos foram inicialmente diluídos em etanol para obtenção das concentrações 0,$05 ; 0,1 ; 0,5 ; 1,0 ; 5,0$ (v/v). Em seguida 1,0 $\mathrm{ml}$ de cada concentração foram colocadas, separadamente, em tubo de ensaios devidamente identificados. Em cada tubo foi adicionado $1,0 \mathrm{~mL}$ da solução de $\mathrm{DPPH}$ $0,02 \%(\mathrm{p} / \mathrm{v})$ recém-preparada. $\mathrm{O}$ material foi submetido à agitação e deixado por 30 minutos em repouso, sob proteção da luz. Após esse período foi realizado a leitura da absorbância em espectrofotômetro a 517 $\mathrm{nm}$. O branco específico foi determinado usando $3,3 \mathrm{~mL}$ de etanol e $0,5 \mathrm{~mL}$ de cada concentração. Como controle positivo foi utilizado o ácido ascórbico $(\mathrm{C}+)$ e como controle negativo foi utilizado a mistura contendo $3 \mathrm{~mL}$ de etanol absoluto, $0,5 \mathrm{~mL}$ de etanol 70\% e 0,3 mL de DPPH 0,5 mM (C-). As amostras foram realizadas em triplicatas e a capacidade de sequestro de radical DP$\mathrm{PH}$ foi calculada de acordo com a equação: Capacidade de sequestro de radical DPPH $(\%)=[(A 0-A 1) / A 0] 100$, onde: $A 0$ foi a $a b-$ sorbância do controle e A1 a absorbância na presença do extrato.

O Método do radical ABTS -+ (2,2'azinobis-(3-ethylbenzthiazoline-6-sulfonic acid) foi realizado conforme a metodologia descrita por Vieira, Sousa e ManciniFilho (2011), com algumas modificações. Inicialmente, foi formado o radical ABTS •+, a partir da reação de $7 \mathrm{mM}$ de ABTS com 2,45 mM de persulfato de potássio, os quais foram incubados à temperatura ambiente e na ausência de luz, por 14 horas. Após esse período, a solução foi diluída em etanol até a obtenção de uma solução com absorbância igual a 0,70 no comprimento de onda de $734 \mathrm{~nm}$ a uma temperatura de equilíbrio de $30{ }^{\circ} \mathrm{C}$. Para realizar as análises, foram adicionados $40 \mu \mathrm{L}$ da amostra diluída a 1960 $\mu \mathrm{L}$ da solução contendo o radical e após 20 minutos foi determinada a absorbância em espectrofotômetro a $734 \mathrm{~nm}$. Como solução-padrão, usou-se o antioxidante sintético Trolox nas concentrações de 100; 200; 400; 800 e 1,000 $\mu \mathrm{M}$ em etanol. Todas as leituras foram realizadas em triplicata, e os resultados foram expressos em $\mathrm{mM}$ de Trolox por grama do extrato.

Os dados obtidos nos ensaios de atividade antioxidante foram analisados estatisticamente com o auxílio do programa BioEstat versão 5.0. Aplicou-se análise de variância (ANOVA) e as diferenças foram determinadas pelo teste de Tukey e foram consideradas significativas a um nível de $5 \%$ ( $p \leq$ $0,05)$.

\section{Atividade antimicrobiana}

A atividade antimicrobiana dos extratos foi investigada através dos ensaios in vitro de difusão em ágar por meio de poço e determinação da Concentração Inibitória Mínima (CIM). Para esses ensaios foram utilizadas as cepas bacterianas Enterococcus faecales (ATCC 29212), Streptococcus pneumoniae (ATCC 49619) e Staphylococcus aureus (ATCC 25923), obtidos junto ao laboratório Labornew.

Os ensaios de difusão em ágar por meio de poço foram realizados conforme a metodologia descrita por Nenaah (2013). As cepas bacterianas foram cultivadas em meio Ágar Mueller-Hinton (AMH) a $37 \stackrel{\circ}{\circ}$ por $24 \mathrm{~h}$. Após esse período as cepas foram suspensas, separadamente, em solução sa- 
lina de $\mathrm{NaCl}$ a $0,85 \%$ e ajustada a uma turbidez de 0,5 da escala de MacFarland, para obtenção dos inócuos bacterianos. Com auxílio de um swab estéril, as cepas foram inoculadas, em placas de Petri com AMH, e nessas placas foram feitas quatro cavidades de $6 \mathrm{~mm}$ de diâmetro com auxílio de pipetas de Pasteur estéreis. Em uma cavidade foram adicionados $20 \mu \mathrm{L}$ de extrato, em outra foram adicionados $20 \mu \mathrm{L}$ de DMSO $0,1 \%$, usado como controle negativo, e nas outras duas cavidades foram adicionados discos com $20 \mu \mathrm{L} / \mathrm{mg}$ de Ciprofloxacina e Gentamicina, usados como controles positivos. As placas foram mantidas em temperatura ambiente por $1 \mathrm{~h}$, para difusão dos tratamentos, e em seguida foram incubadas a $37{ }^{\circ} \mathrm{C}$ por $24 \mathrm{~h}$. Após esse período, os halos de inibição formados em volta das cavidades foram mensurados com o auxílio de uma escala milimétrica. $O$ experimento foi realizado em triplicatas. Os dados obtidos foram expressos como média \pm desvio pa-

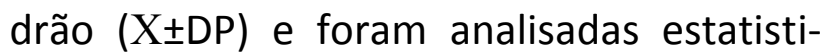
camente usando análise de variância (ANOVA), comparadas pelo teste de Tukey, usando o software Bioestat versão 5.3. As diferenças foram consideradas significativas quando $p \geq 0,05$.

Para determinar a Concentração Inibitória Mínima (CIM) foi realizado o método de microdiluição, conforme as normativas estabelecidas pelo NCCLS (2003). As cepas foram normalizadas para uma concentração com base no padrão 0,5 da escala de McFarland. Em ensaios independentes, utilizando placas de 96 poços contendo caldo Muller-Hinton (CMH), $5 \mu \mathrm{L}$ de inócuo bacteriano e $100 \mu \mathrm{L}$ de extrato foram adicionados em cada poço, para um volume final de 200 $\mu \mathrm{L}$. Como controle negativo foi utilizado DMSO $0,01 \%$ e como controles positivos os antibióticos Ciprofloxacina e Gentamicina. Em seguida as placas foram acondicionadas em incubadora bacteriológica a $37{ }^{\circ} \mathrm{C}$, durante $24 \mathrm{~h}$. A CIM foi definida como a menor concentração do extrato que inibiu o crescimento bacteriano visível, confirmado pela adição de $30 \mu \mathrm{L}$ da solução resazurina $0,01 \%$, duas horas após a sua aplicação. Os experimentos foram realizados em triplicatas para concentrações de $500 \mu \mathrm{g} / \mathrm{mL}$ até $7,8 \mu \mathrm{g} / \mathrm{mL}$.

\section{RESULTADOS E DISCUSSÃO}

\section{Atividade antioxidante}

Os resultados do conteúdo de fenólicos totais dos extratos ECCQ e ECLL encontramse apresentados na Figura 1.

Figura 1 - Teor de fenólicos (e eg. ácido gálico/mL) do extrato da casca do caule de C. quercifolius (ECCQ) e do extrato da casca do caule de L. leucocephala. (ECLL).

Figure 1 - The levels of phenolics (e eg. acid gallic $/ \mathrm{mL}$ ) of crude extracts steam bark of $C$. quercifolius (ECCQ) and of L. leucocephala. (ECLL).

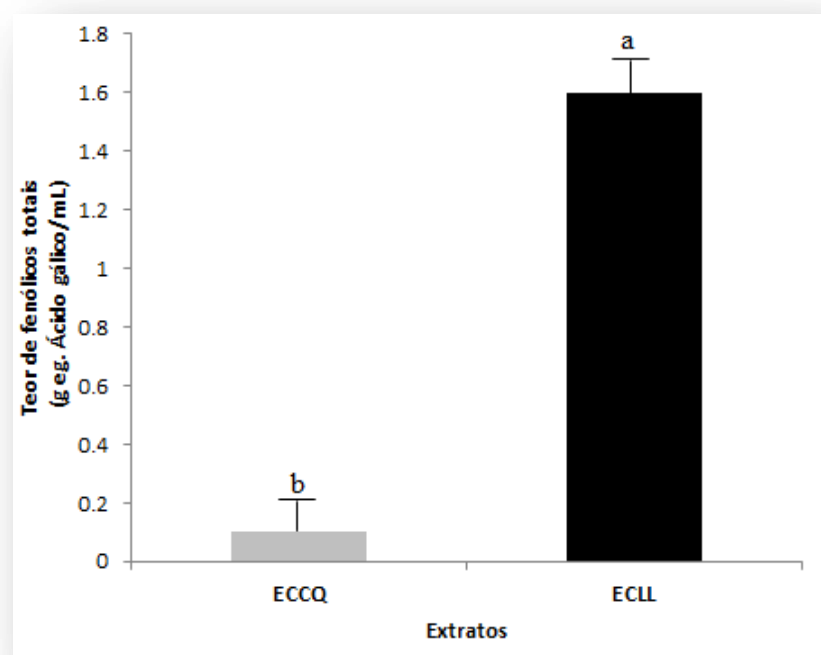

${ }^{a}$ valores significativos $(p<0,05)$

A investigação de compostos fenólicos pode ser justificada pelo fato desses compostos estarem associados à prevenção de 
doenças crônico-degenerativa, conforme afirmam Coutinho, Muzitano e Costa (2009). Sabe-se que é possível haver uma relação direta entre a bioatividade desses compostos e seu potencial antioxidante, que em geral é atribuído diretamente à atividade sequestrante de radicais livres (PAULA; SANTOS; PINTO, 2015).

Nesta pesquisa, o extrato etanólico da casca do caule de L. leucocephala apresentou valores mais altos para teor de compostos fenólicos; os valores obtidos estão acima dos registrados por Benjakul et al (2014), que investigaram a atividade antioxidante do extrato etanólico e aquoso das folhas de L. leucocephala. Segundo Soares et al. (2008), é comum observar discrepância de valores em ensaios biológicos iguais para a mesma espécie, uma vez que a presença de biomoléculas está relacionada a fatores bióticos e abióticos, tais quais maturação, práticas de cultivo, origem geográfica, estágio de crescimento, condições de colheita e processo de armazenamento dos extratos. Os resultados do teor fenólico de $E C C Q$, obtidos nesta pesquisa, estão condizentes com o de Oboh (2005), que, investigando a atividade antioxidante de extratos foliares, detectou uma baixa concentração de compostos fenólicos.

De acordo com Alves et al. (2010), devido aos diferentes tipos de radicais livres e suas diferentes formas de atuação nos organismos vivos, não existe um método universal pelo qual pode-se avaliar de forma precisa a atividade antioxidante, sendo os mais comuns aqueles que avaliam essa atividade através dos sistemas geradores de radicais livres. Nesta pesquisa, a atividade antioxidante dos extratos etanólicos da casca do caule de $C$. quercifolius e de $L$. leucocephala foi analisada através dos testes antiradicalares com os radicais DPPH e ABTS.

O ECLL apresentou uma maior capacidade sequestrante de radicais DPPH em comparação com o ECCQ (Figura 2). Quanto à capacidade sequestrante do radical ABTS, os melhores resultados também foram registrados para $E C L L \quad\left(E C_{50}=3,60 \pm 0,45\right.$ $\mu \mathrm{g} / \mathrm{mL}$ ), enquanto para $E C C Q$, foi registrada uma baixa capacidade de sequestro do radical ABTS $\left(E_{50}=0,14 \pm 0,05 \mu \mathrm{g} / \mathrm{mL}\right)$. Os resultados da atividade antioxidante pelo método ABTS foram expressos como capacidade antioxidante total equivalente ao Trolox.

Figura 2 - Capacidade antioxidante (sequestradora de radical DPPH) do extrato da casca do caule de $C$. quercifolius (ECCQ) e do extrato da casca do caule de L. leucocephala (ECLL).

Figure 2 - Antioxidant capacity (DPPH radical scavenging) of the stem bark extract of $C$. quercifolius (ECCQ) and stem bark extract of L. leucocephala (ECLL).

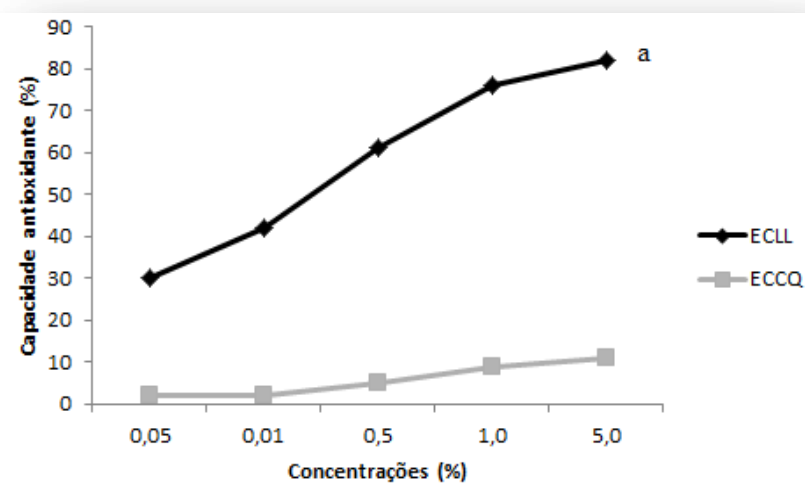

a valores significativos $(p<0,05)$

Com esses resultados pode-se afirmar que, nesta pesquisa, houve uma relação entre o teor de fenólicos totais e a capacidade antioxidante dos extratos analisados. Com o ECLL apresentando teor de fenólicos totais maior e a maior capacidade antioxidante, tanto utilizando os radicais DPPH, como os radicais ABTS. 


\section{Atividade antimicrobiana}

A triagem de extratos vegetais para detecção de atividade antimicrobiana tem sido fonte de inúmeros agentes terapêuticos, permitindo acesso a um grande número de compostos potencialmente ativos e quimicamente interessantes para o desenvolvimento de novos agentes antimicrobianos (SAMY; GOPALAKRISHNAKONE, 2010).

Nesta pesquisa, os extratos ECCQ e ECLL não foram capazes de inibir o crescimento das espécies bacterianas $E$. faecales, $S$. pneumoniae e $S$. aureus, em nenhuma das concentrações testadas (Tabela 1).

Tabela 1 - Atividade antimicrobiana dos extratos da casca de caule das espécies L. leucocephala (ECLL) e C. quercifolius (ECCQ), em diferentes concentrações através do ensaio por difusão em poço, frente a diferentes espécies bacterianas Table 1 - Antimicrobial activity of stem bark extracts of the species L. leucocephala (ECLL) and C. quercifolius (ECCQ) in different concentrations by testing for diffusion well, against different bacterial species.

\begin{tabular}{cccc}
\hline Tratamentos & \multicolumn{3}{c}{ Médias das zonas de Inibição (mm \pm DP) } \\
\cline { 2 - 4 } & E. faecales & S. pneumoniae & S. aureus \\
\hline ECLL & \multicolumn{3}{c}{} \\
$500 \mu \mathrm{g} / \mathrm{mL}$ & $16,0 \pm 1.0^{c}$ & $1,5 \pm 0,5^{\mathrm{c}}$ & $2,0 \pm 0,5^{\mathrm{c}}$ \\
$250 \mu \mathrm{g} / \mathrm{mL}$ & $16,5 \pm 0,5^{\mathrm{c}}$ & $\mathrm{NA}$ & $2,0 \pm 0,5^{\mathrm{c}}$ \\
$125 \mu \mathrm{g} / \mathrm{mL}$ & $16,5 \pm 0,5^{\mathrm{c}}$ & $\mathrm{NA}$ & $\mathrm{NA}$ \\
$62.5 \mu \mathrm{g} / \mathrm{mL}$ & $\mathrm{NA}$ & $\mathrm{NA}$ & $\mathrm{NA}$ \\
$31.2 \mu \mathrm{g} / \mathrm{mL}$ & $\mathrm{NA}$ & $\mathrm{NA}$ & $\mathrm{NA}$ \\
$15.6 \mu \mathrm{g} / \mathrm{mL}$ & $\mathrm{NA}$ & $\mathrm{NA}$ & $\mathrm{NA}$ \\
$7.8 \mu \mathrm{g} / \mathrm{mL}$ & $\mathrm{NA}$ & $\mathrm{NA}$ & $\mathrm{NA}$ \\
\hline $\mathrm{ECCQ}$ & & & \\
$500 \mu \mathrm{g} / \mathrm{mL}$ & $5,0 \pm 0,5^{\mathrm{c}}$ & $12,0 \pm 0,5^{\mathrm{c}}$ & $12,0 \pm 0,5^{\mathrm{c}}$ \\
$250 \mu \mathrm{g} / \mathrm{mL}$ & $\mathrm{NA}$ & $\mathrm{NA}$ & $5,0 \pm 0,5^{\mathrm{c}}$ \\
$125 \mu \mathrm{g} / \mathrm{mL}$ & $\mathrm{NA}$ & $\mathrm{NA}$ & $5,0 \pm 1,0^{\mathrm{c}}$ \\
$62.5 \mu \mathrm{g} / \mathrm{mL}$ & $\mathrm{NA}$ & $\mathrm{NA}$ & $\mathrm{NA}$ \\
$31.2 \mu \mathrm{g} / \mathrm{mL}$ & $\mathrm{NA}$ & $\mathrm{NA}$ & $\mathrm{NA}$ \\
$15.6 \mu \mathrm{g} / \mathrm{mL}$ & $\mathrm{NA}$ & $\mathrm{NA}$ & $\mathrm{NA}$ \\
$7.8 \mu \mathrm{g} / \mathrm{mL}$ & $\mathrm{NA}$ & $\mathrm{NA}$ & $\mathrm{NA}$ \\
\hline Ciprofloxacina & $32,5 \pm 0,5^{\mathrm{a}}$ & $30,0 \pm 0,5^{\mathrm{a}}$ & $28,5 \pm 0,5^{\mathrm{a}}$ \\
Gentamicina & $21,5 \pm 0,5^{\mathrm{b}}$ & $22,0 \pm 0,5^{\mathrm{b}}$ & $22,0 \pm 0,5^{\mathrm{b}}$ \\
DMSO 0,01\% & $\mathrm{NA}$ & $\mathrm{NA}$ & $\mathrm{NA}$ \\
\hline
\end{tabular}

Na mesma coluna, médias seguidas de letras iguais não diferem estatisticamente em si $(p \leq 0,05)$. NA = não ativo.

Esses resultados diferem dos registrados por Sahar et al. (2015) que observaram ini- bição de crescimento das espécies bacterianas E. coli e Salmonela typhimurium, tratadas com extrato foliar de L. leucocephala, apresentando halo de inibição de

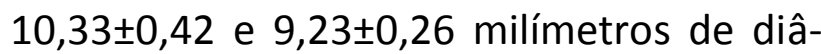
metro, respectivamente; valores considerados significativos quando comparados com o fármaco padrão.

Nesta pesquisa, não houve registro de CIM até a máxima concentração testada (500 $\mu \mathrm{g} / \mathrm{mL}$ ) (Tabela 2).

Tabela 2 - Concentração Inibitória Mínima (CIM) dos extratos da casca de caule das espécies $L$. leucocephala (ECLL) e $C$. quercifolius (ECCQ), em diferentes concentrações, frente a diferentes espécies bacterianas.

Table 2 - Minimum Inhibitory Concentration (MIC) of the stem bark extracts of the species L. leucocephala (ECLL) and C. quercifolius (ECCQ) in different concentrations against different bacterial species.

\begin{tabular}{cccc}
\hline Tratamentos & \multicolumn{3}{c}{ CIM $(\mu \mathrm{g} / \mathrm{mL})$} \\
\cline { 2 - 4 } & E. faecales & S. pneumoniae & S. aureus \\
\hline ECLL & $>500$ & $>500$ & $>500$ \\
\hline ECCQ & $>500$ & $>500$ & $>500$ \\
\hline
\end{tabular}

De acordo com Djipa, Delmee e QuentinLecler (2000), ação de moléculas bioativas presentes em extratos vegetais pode variar de acordo a espécie bacteriana no qual está sendo testado. Sabe-se, por exemplo, que a atividade antimicrobiana de extratos aquosos podem variar frente a bactérias grampositivas e gram-negativas. Como nesta pesquisa as espécies bacterianas testadas são todas gram-positivas, e os dados obtidos por Sahar et al. (2015) potencializam a atividade antimicrobiana do extrato foliar de L. leucocephala frente a bactérias gramnegativas, sugere-se continuar a investigação frente a bactérias com essas características. Além do que, os resultados apresentados por Sahar et al. (2015), foram obtidos a partir de ensaios com extratos foliares; enquanto nesta pesquisa foi usado extrato da casca do caule. Segundo Harvey, Edrada- 
Ebel e Quinn (2015), a potencialidade biológica das moléculas presentes no extrato pode variar de acordo com a parte vegetal utilizada e com o solvente utilizado no processo de extração.

No que concerne a atividade antimicrobiana da espécie $C$. quercifolius os resultados obtidos nesta pesquisa estão condizentes com os registrados por PeixotoSobrinho et al. (2012), que não observaram inibição de crescimento dos isolados clínicos bacterianos E. faecalis e S. aureus, quando tratados com extrato etanólico do caule.

\section{CONCLUSÃO}

O extrato etanólico da casca do caule da espécie Leucaena lecocephala apresentou uma elevada atividade antioxidante, através da atividade sequestradora dos radicais DPPH e ABTS; atividade não observada nos ensaios com o extrato da espécie Cnidoscolus quercifolius. Foi observado existir uma correlação direta entre a quantidade de fenólicos totais e a atividade antioxidante na espécie $L$. lecocephala.

Os extratos de $L$. lecocephala e $C$. quercifolius não apresentaram atividade antimicrobiana frente às espécies bacterianas $E$. faecales, S. pneumoniae e S. aureus.

\section{REFERÊNCIAS}

AGRA, M. F.; et al. Medicinal and poisonous diversity of the flora of "cariri paraibano", Brazil. Journal of Ethnopharmacology, v.111, p.383-395, 2007.

ALVES, C. Q.; et al. Métodos para determinação de Atividade Antioxidante in Vitro em substratos Orgânicos. Química Nova, v. 33, n.10, p. 2202-2210, 2010.
ARAÚJO, R. M. S. de; et al. A new exogen anticoagulant with high selectivity to intrinsic pathway of coagulation. Thrombosis research, v. 128, p. 395-397, 2011.

BENJAKUL, S. B.; et al. Antioxidant activities of lead (Leucaena leucocephala) seed as affected by extraction solvent, prior dechlorophyllisation and drying methods. Journal Food Science and Technology, v. 51, n.11, p.3026-3037, 2014.

BRAGA, R. Plantas do Nordeste, especialmente do Ceará, v. 8 . 3 ed. Fortaleza: Imprensa Oficial do Ceará, 2004.

COUTINHO, M. A. S.; MUZITANO, M. F.; COSTA, S. S. Flavonoides, potenciais agentes terapêuticos para o processo inflamatório. Revista Virtual Química. v. 1, n. 3, p. 24156, 2009.

DJIPA, C. D.; DELMEE, M.; QUENTIN-LECLER, C. Q. J. Antimicrobial Activity of bark extracts of Syzygium jambos (Myrtaceae). Journal of Ethnopharmacology, v.71, p.307313, 2000.

FAUCI, A.; MARSTON, H. The perpetual challenge of antimicrobial resistance. Journal of the American Medical Association, v. 311, n. 18, p. 1853-1854, 2014.

HARVEY, A. L.; EDRADA-EBEL, R.; QUINN, R. $J$. The re-emergence of natural products for drug discovery in the genomics era. Nature Reviews Drug Discovery, 2015. Disponível em: <doi: $10.1038 / \mathrm{nrd} 4510>$.

KUPPUSAMY, U. R.; et al. Leucaena leucocephala Fruit Aqueous Extract Stimulates Adipogenesis, Lipolysis, and Glucose Uptake in Primary Rat Adipocytes. Scientific World Journal. 2014. Disponível em: <http:// dx.doi.org/10.1155/ 2014/737263>.

MISHRA, B.; TIWARI, V. K. Natural products: An evolving role in future drug discovery. European Journal of Medicinal Chemistry. v. 46, p. 4769-4807, 2011. 
NCCLS. Clinical and Laboratory Standards institute. Performace standards for antimicrobial disk susceptibility tests: approved standard. Wayne, Pennsylvania, 2003.

NENAAH, G. Antimicrobial activity of Calotropis procera Ait (Asclepiadaceae) and isolation of four flavonoid glycosides as the active constituents. World Journal of Microbiology and Biotechnology. v. 29, n. 1, p. 1255-1262, 2013.

$\mathrm{OBOH}, \mathrm{G}$. Effect of some post-harvest treatments on the nutritional properties of cnidoscolus acontifolus leaf. Pakistan Journal Nutrition, v.4, n.4, p.226-230, 2005.

PAULA, R. A. O.; SANTOS, E. S.; PINTO, L. F. Determinação da atividade antioxidante in vitro das bebidas de café e chás verde e preto. Revista de Ciências Farmacêuticas Básica e Aplicada, v. 36, n. 2, p. 167-171, 2015.

PEIXOTO-SOBRINHO, T. J. S.; et al. Phytochemical screening and antibacterial activity of four Cnidoscolus species (Euphorbiaceae) against standard strains and clinical isolates. Journal of Medicinal Plants Research, v. 6, n.21, p.3742-3748, 2012.

RAFIEIAN-KOPAEI, M. Medicinal plants and the human needs. Journal of HerbMed Pharmacology. v.1, n.1, p.1-2, 2012.

RIBEIRO-FILHO, N. M. Avaliação comparada dos indicies químicos nitrogênio e fósforo nas porções morfológicas dos espécimes de faveleira com espinho e sem espinho. Revista Brasileira de Produtos Agroindustriais, v. 9, n. 2, p. 149-160, 2007.

RIZINNI, C. T. Botânica Econômica Brasileira. 2 ed. São Paulo: Âmbito Cultura Ed. Ltda, 1995.

RODAL, M. J. N.; SAMPAIO, E. V. S. B. A vegetação do bioma caatinga. In: SAMPAIO, E. V. S. B.; GIULIETTI, A. M.; VIRGÍNIO, J. ; GAMARRA-ROCHA, C. F. L. (Ed.). Vegetação \&
Flora da Caatinga Associada Plantas do Nordeste /Centro Nordestino de Informação sobre Plantas, Recife, 2002. p. 49-90.

SAHAR, M.; et al. Antioxidant, antimicrobial activities of flavonoids glycoside from Leucaena leucocephala leaves Reda S. Journal of Applied Pharmaceutical Science, v. 5, n. 06, p. 138-147, 2015.

SAMY, R. P.; GOPALAKRISHNAKONE, P. Therapeutic Potential of Plants as Antimicrobials for Drug Discovery. eCAM. v. 7, n.3, p. 283-294, 2010.

SILVA, I. L.; COELHO, L. C. B. B.; SILVA, L. A. O. Biotechnological Potential of the Brazilian Caatinga Biome. Advances in Research. v.5, n.1, p.1-17, 2015.

SOARES, M.; et al. Compostos fenólicos e atividade antioxidante da casca de uvas niágara e isabel. Revista Brasileira de Fruticultura, Jaboticabal, v. 30 , n. 1, p. 059-064, 2008.

VIEIRA, L. M.; SOUSA, M. S. B.; MANCINIFILHO, J. Fenólicos totais e capacidade antioxidante in vitro de polpas de frutos tropicais. Revista Brasileira de Fruticultura, v. 33, n. 3, p. 888-897, 2011.

\section{(c) (1) access article distributed under the terms of the Creative Commons Attribution License, which permits unrestricted use, distribution, and reproduction in any medium, provi- ded the original work is properly cited.}

Artigo recebido em 18 de abril de 2016 .

Avaliado em 29 de abril de 2016.

Aceito em 04 de maio de 2016.

Publicado em 25 de maio de 2016.

Como citar este artigo (ABNT):

NUNES, Fábio Rogério Santos; DIAS, Hosana Maria Cordeiro; CAVALCANTE, Giani Maria. Investigação das atividades antioxidante e 
antimicrobiana de duas espécies arbóreas ocorrentes no bioma caatinga. Estação Científica (UNIFAP), Macapá, v. 6, n. 1, p. 8190, jan./abr. 2016. 